\title{
ANNOUNCEMENT
}

\section{Visual Neuroscience Young Investigator Award}

Dr. Cole Graydon (left) received the 2016 VNS Young Investigator Award at the biennial Retinal Neurobiology and Visual Processing FASEB Meeting in Keystone, Colorado. The award was presented by Dr. Steven H. DeVries (right), the 2016 meeting organizer. Dr. Graydon's work was selected from among many outstanding studies that were presented at this meeting. The title of his presentation was, "Synaptic transfer between ON and OFF visual channels mediated by AII amacrine cells in mouse retina". Dr. Graydon is working on unraveling the mechanisms of rod signaling in the mammalian retina. His findings indicate that the AII amacrine cell acts as a temporal filter in the mammalian retina, passing transient signals with great sensitivity while eliminating sustained information. Dr. Graydon conducted these studies in the laboratory of Dr. Jeff Diamond at the Synaptic Physiology Section of the National Institute of Neurological Disorders and Stroke in Bethesda, MD.

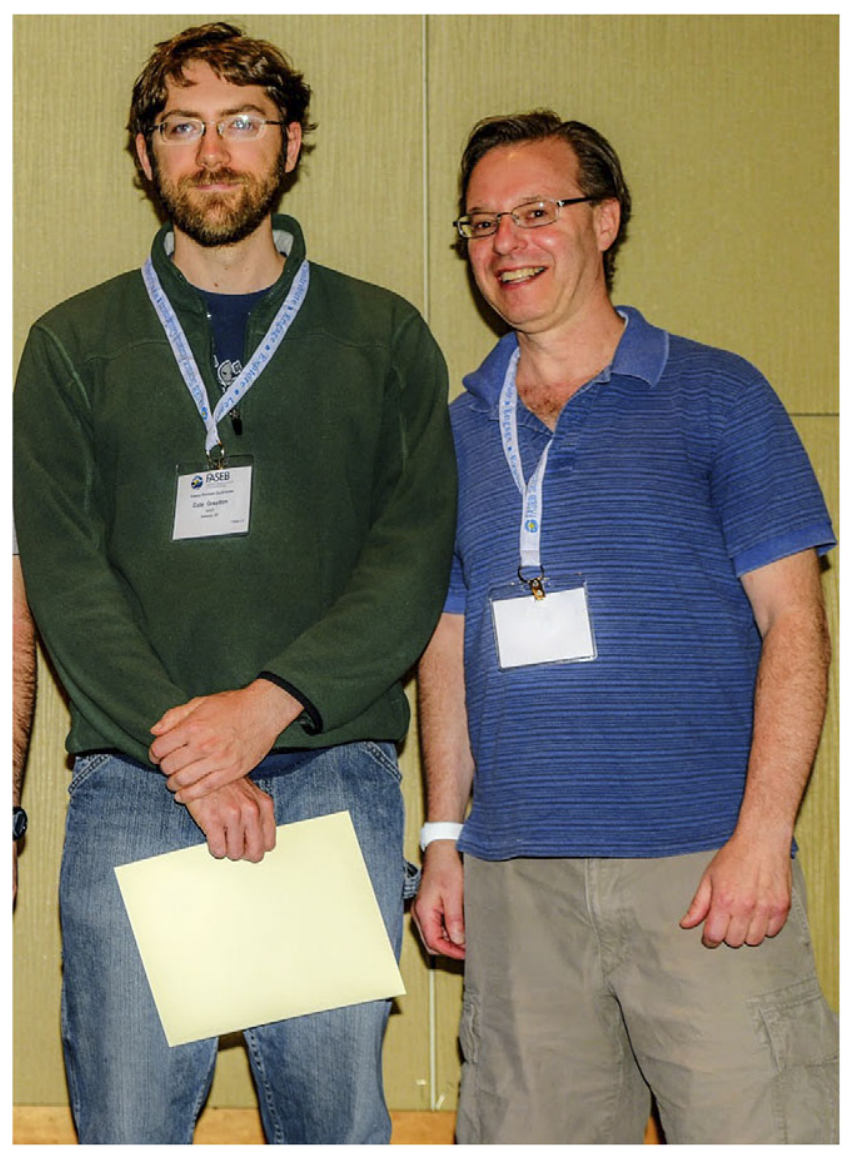

